\title{
UM ÁBACO PARA ENSINAR FRAÇÕES
}

Wojciech Andrzej Kulesza Universidade Federal da Paraíba wakulesza@gmail.com

\section{RESUMO}

Este artigo objetiva descrever como a voga do ensino intuitivo no último quartel do século XIX, por intermédio do incentivo à utilização de materiais concretos, influenciou o modo de se ensinar a aritmética elementar no Brasil. Focalizando a apropriação feita por Abílio César Borges (18241891), o Barão de Macaúbas, de materiais didáticos produzidos na Europa para uso em suas escolas, o trabalho se baseia fundamentalmente em sua conferência acerca do aritmômetro fracionário de sua invenção durante a Exposição Pedagógica do Rio de Janeiro em 1883.

Palavras-chave: Ábacos. Ensino de frações. Materiais didáticos.

\section{AN ABACUS TO TEACH FRACTIONS ABSTRACT}

This article aims to describe how the vogue of intuitive teaching in the last quarter of the nineteenth century, by encouraging the use of concrete materials, influenced the way of teaching elementary arithmetic in Brazil. Focusing on the appropriation made by Abílio César Borges (1824-1891), the Baron de Macaúbas, of didactic materials produced in Europe for use in his schools, the work is based fundamentally on his conference about the fractional arithmometer of his invention during the pedagogical exhibition of Rio de Janeiro in 1883.

Keywords: Abacuses. Learning fractions. Leaching materials.

\section{UN ÁBACO PARA ENSEÑAR FRACCIONES RESUMEN}

El objetivo de este artículo es describir cómo la boga de la enseñanza intuitiva en el último cuartel del siglo XIX, por el incentivo a la utilización de materiales concretos, influenció el modo de enseñar la aritmética elemental en Brasil. En el marco de la apropiación hecha por Abílio César Borges (1824-1891), el Barón de Macaúbas, de materiales didácticos producidos en Europa para uso en sus escuelas, el trabajo se basa fundamentalmente en la conferencia acerca del aritmómetro fraccionario de su invención durante la Exposición Pedagógica de Río de Janeiro en 1883.

Palabras claves: Ábacos. Enseñanza de fracciones. Materiales didácticos. 


\section{UN ABAQUE POUR L'ENSEIGNEMENT DES FRACTIONS RÉSUMÉ}

Cet article vise à décrire comment la vogue de l'enseignement intuitif au cours du dernier quart du XIXe siècle, en encourageant l'utilisation de matériaux concrets, a influencé la manière d'enseigner l'arithmétique élémentaire au Brésil. En se concentrant sur l'appropriation faite par Abílio César Borges (1824-1891), le baron de Macaúbas, de matériel didactique produit à l'étranger pour être utilisé dans ses écoles, le travail repose essentiellement sur sa conférence sur l'arithmomètre fractionnel de son invention lors de l'exposition pédagogique de Rio de Janeiro en 1883.

Mots-clés: Abaques. Enseignement des fractions. Matériel didactique.

\section{INTRODUÇÃO}

Diversos formatos de ábacos têm sido utilizadas como instrumentos de representação e operação com quantidades numéricas remontando sua utilização aos primeiros tempos do desenvolvimento da escrita. Enquanto a representação dos números acompanhava os avanços da escrita, dando origem inclusive a numerações alfabéticas, as operações realizadas nos ábacos recorriam a materiais diversos, desde o pó de areia espalhado numa base de pedra onde se traçavam linhas ou colunas para receber seixos, sementes e outros pequenos objetos, até os ábacos atuais com suas contas ou miçangas alinhadas, vertical ou horizontalmente, enfiadas em arames. Utilizados largamente pelos antigos gregos e romanos, seu uso como instrumento de cálculo foi sobrepujado paulatinamente no Ocidente pela introdução - a partir do século XIII - dos algarismos indo-arábicos e do sistema posicional utilizados por nós até hoje. Todavia, a realização das quatro operações sobre o ábaco sobreviveu até o final do século XVIII no Ocidente e permanece viva até hoje em diversos países do Oriente (SCHÄRLIG, 2001, p. 162 e ss).

A partir do século XIX a trajetória histórica do ábaco seguiria por duas vertentes distintas: como instrumento de cálculo e como recurso para o ensino da aritmética. Como aparelho para calcular, ele passaria rapidamente de contador manual a mecânico: já em 1821, Thomas de Colmar criaria na França o primeiro contador mecânico produzido em massa, abrindo o caminho para o surgimento das modernas calculadoras, precursoras dos atuais computadores. Como material pedagógico, o ábaco foi rapidamente incorporado ao chamado "ensino intuitivo", a partir da sistematização feita por Pestalozzi (1746-1827), favorecendo a manipulação concreta dos objetos, especialmente na educação infantil. Daí em diante, o ábaco, em seus diversos tipos construídos 


\section{$(\mathrm{cc}) \mathbf{E Y}$}

com diferentes materiais, passou a ser um material obrigatório para o ensino da aritmética, fazendo parte dos catálogos de material escolar oferecidos por empresas especializadas para uso das escolas (CARRILlO GALLEGO, 2018). Como Colmar havia denominado seu contador de aritmômetro, sua ampla difusão como "máquina de calcular", fez com que o ábaco também ficasse conhecido como aritmômetro escolar. A Figura 1 abaixo mostra um ábaco escolar típico em uso nas escolas contemporâneas.

No Brasil, a voga do "ensino intuitivo" ou das "lições de coisas", que havia colocado em evidência a utilização do ábaco nas escolas, se intensifica a partir da década de 1870 e seus princípios são incorporados na legislação pela Reforma Leôncio de Carvalho de 1879. Já no regimento das escolas públicas da Corte de 1883 o ensino era pautado pelo "método intuitivo", indicando inclusive que "o Estado deveria fornecer os objetos necessários para a prática ou auxílio do método intuitivo, sempre que fosse possível fazer aquisição” (CASTANHA, 2012, p. 286). No caso específico do ensino da matemática, o regimento cita explicitamente o uso de um "contador mecânico", a ser utilizado pelos alunos "para fixar os números e introduzir os conceitos das quatro operações fundamentais da aritmética" (CASTANHA, 2012, p. 287).

FIGURA 1 - Ábaco Escolar

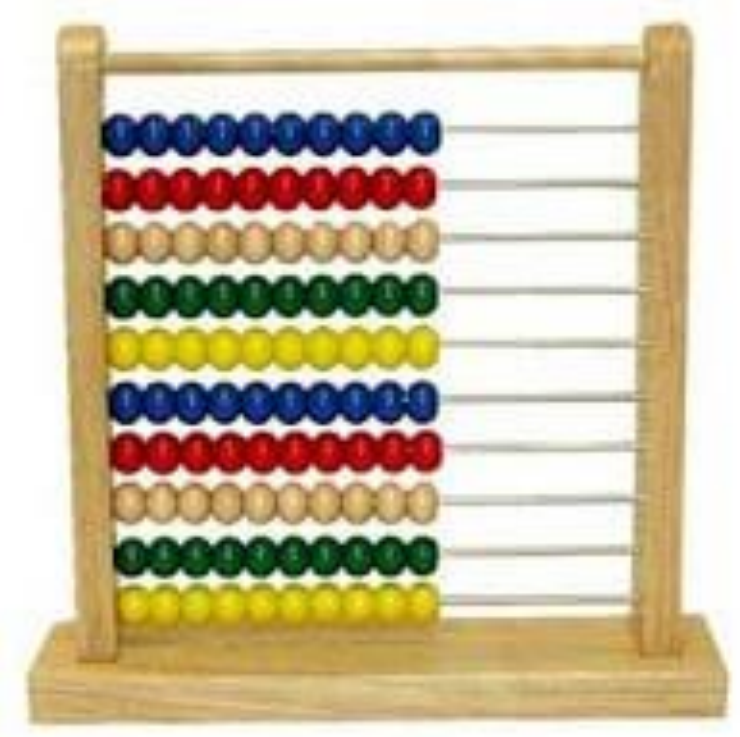

Fonte: https://pedagogiadamatematica.files.wordpress.com/2015/09/abaco-escolar.jpg?w=646 
No levantamento feito por Oliveira (2014) das prescrições legais referentes ao ensino de aritmética, constantes da legislação educacional de diversos Estados brasileiros, podemos ver que o uso de ábacos no ensino não se restringiu ao Município da Corte, mas estendeu-se por todo o país. Em torno do final do século XIX e início do século XX os ábacos utilizados nas escolas passaram a ter outras denominações, como contador, contador mecânico, aritmômetro, e também a incorporar outros conteúdos de ensino, como tabuadas, unidades de medida, frações, dentre outros. No Brasil, com a generalização do sistema métrico decimal a partir de 1870, passaram a ser inscritas nos ábacos, além de números, abreviaturas de unidades de medida, especialmente as de comprimento e massa, metro e quilograma, perfeitamente harmonizáveis com o ensino do sistema de numeração decimal.

Como acontecia com outros materiais, tais como livros, mapas, quadros parietais e mobiliário escolar, a grande maioria desses ábacos era importada do exterior e adaptada à nossa realidade. A ampla vitrine onde donos de escolas e autoridades educacionais iam buscar esses materiais eram as mostras pedagógicas realizadas paralelamente às grandes exposições internacionais. Nessas mostras de materiais didáticos se exibiam os novos recursos postos à disposição dos professores e das escolas para lidar com o ensino. Como mostrou Kuhlman Júnior, nessas exposições era flagrante "a vinculação entre novos materiais didáticos e métodos pedagógicos" (2001, p. 198), ou seja, procurava-se expressar por meio de objetos materiais as novas concepções de ensino e aprendizagem. Cada exposição deveria traduzir o estado em que se encontravam as ideias e ações pedagógicas naquele momento nos diversos países participantes.

Este artigo objetiva descrever como a voga do ensino intuitivo no último quartel do século XIX influenciou o modo de se ensinar a aritmética elementar no Brasil. Focalizando a apropriação feita por Abílio César Borges (1824-1891), o Barão de Macaúbas, de materiais didáticos produzidos no exterior para uso em suas escolas, o trabalho se baseia fundamentalmente em sua ativa participação na Exposição Pedagógica do Rio de Janeiro em 1883. Médico, nomeado Diretor Geral dos Estudos na Bahia, Borges fundou em 1858 o Ginásio Baiano em Salvador, o Colégio Abílio em 1871 no Rio de Janeiro, abrindo uma filial desse Colégio em 1881 em Barbacena, Minas Gerais (SAVIANI, 2000). Durante esse tempo realizou diversas viagens ao exterior de onde trouxe materiais didáticos, além de ter redigido e publicado alguns compêndios em editoras estrangeiras.

Comissionado pelo governo brasileiro para participar do Congresso Pedagógico Internacional realizado em Buenos Aires em 1882, o Barão foi certamente um dos incentivadores 


\section{(cc) $\mathrm{EY}$}

da realização de um congresso semelhante no Rio de Janeiro. Esse Congresso de Instrução, previsto para ser realizado a partir de $1^{\circ}$ de junho de 1883 , foi cancelado poucos dias antes, mantendo-se, todavia, a mostra de materiais didáticos, muitos deles já desembarcados no porto do Rio de Janeiro (COLLICHIO, 1987). Durante a mostra, denominada Exposição Pedagógica do Rio de Janeiro, aberta ao público de 29 de julho a 30 de setembro daquele ano, foram realizadas várias conferências, dentre as quais uma de Borges "acerca do aritmômetro fracionário de sua invenção" pronunciada num sábado, véspera do encerramento da Exposição. A Figura 2 abaixo reproduz a página de rosto da publicação derivada de sua conferência.

\section{O APARELHO ESCOLAR MÚLTIPLO DO BARÃO DE MACAÚBAS}

O Barão de Macaúbas inicia sua palestra criticando o modo como era ministrado o ensino na época, caracterizado, segundo ele, "pela ausência de método", situação essa ainda "mais sensível e mais danosa" no que se referia ao ensino da aritmética (BORGES, 1884, p. 1). ${ }^{1}$ A tônica de sua crítica reside no excesso de verbalismo e na ênfase na memorização. Eis sua descrição de como se iniciava o ensino de aritmética entre nós: "Ainda bem não sabem os meninos distinguir os algarismos uns dos outros, metem logo em suas mãos as célebres tabuadas, e mandam-lhes que as decorem, casa por casa, sem a mínima intervenção da inteligência, e da consciência portanto" (BORGES, 1884, p. 5). Depois de apresentar evidência de que o ensino precisa ser reformado, o Barão conta que desde que fundou seu primeiro colégio em 1858 começou a pensar em como se poderia melhorar o ensino de aritmética dos meninos e "tendo observado depois na Europa o vantajoso emprego que do contador mecânico faziam os mestres primários em tal ensino, apenas fundei o Colégio Abílio, em 1871, mandei construir um, que desde então tem prestado os melhores serviços” (BORGES, 1884, p. 7).

Aventando a precedência dessa introdução do ábaco no ensino primário do Rio de Janeiro, Borges afirma que desde que chegou no Rio de Janeiro em 1869, em visita às "principais escolas públicas e particulares", encontrou apenas uma que possuísse "tão útil instrumento de ensino". Foi na escola da "professora D. Colonia, que sendo baiana, dali havia trazido aquele contador", acrescentando que, com a morte daquela professora, adquiriu o contador para seu colégio em Barbacena (BORGES, 1884, p. 7). Como importante praça de comércio no início do século XIX,

\footnotetext{
${ }^{1}$ Optamos por atualizar a ortografia dos textos da época.
} 


\section{$(\mathrm{cc})$ EY}

a cidade de Salvador na Bahia certamente recorria a abacistas, para fazer a contabilidade de suas transações. Como em toda corporação cuidava da formação de aprendizes do ofício, supomos que foi por intermédio desses artífices que D. Colonia tomou conhecimento desse instrumento.

Segundo o Barão, a partir de 1873 o uso dos contadores mecânicos no Rio de Janeiro passou a se generalizar graças à sua atuação na época como membro do Conselho Superior de Instrução demonstrando as vantagens que estava colhendo como o uso do aparelho em seu colégio. Tão convencido ele estava da necessidade do ábaco para o ensino de aritmética que acrescentou a seguinte nota de rodapé ao texto publicado da conferência:

Posso assegurar que rara será a escola primária dos Estados Unidos, da Alemanha, da Suécia, da Dinamarca, da Suíça, da Bélgica, da França, da Inglaterra e outros países, que não possua hoje seu contador mecânico de inteiros. Tão universal é hoje a opinião dos mais distintos pedagogos de que o primeiro ensino do cálculo deve ser dado concretamente, isto é, intuitivamente (BORGES, 1884, p. 36).

FIGURA 2 - Conferência do Barão de Macaúbas

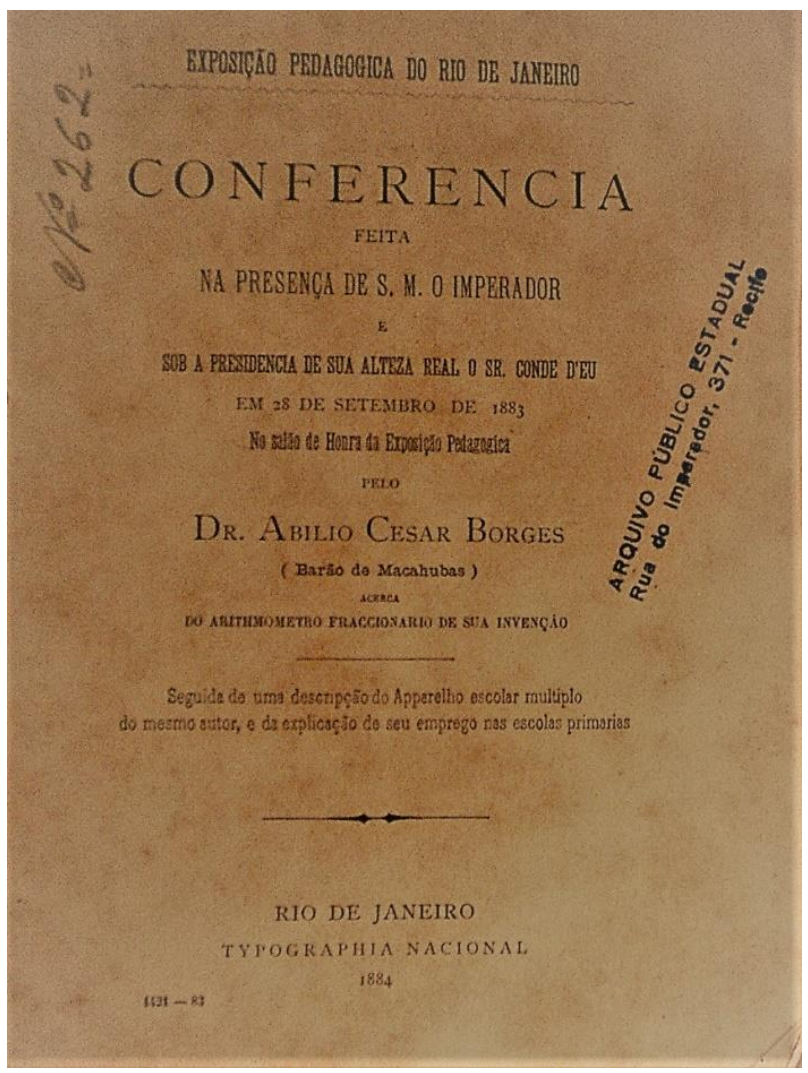

Fonte: Arquivo Público Estadual de Pernambuco 
Todavia, ele se queixa que, excetuando algumas escolas públicas localizadas nas capitais das províncias e no Rio de Janeiro, ainda havia poucas escolas que possuíam o instrumento e, mesmo assim, ele coloca em dúvida se os ábacos que existiam estão sendo "empregados como convém". Para ilustrar o desconhecimento existente a respeito do contador mecânico ele conta que "não há muitos dias, aqui mesmo, na sala da Exposição do Colégio Abílio, dois cavalheiros, aliás inteligentes e de elevada posição social, perguntavam a meus filhos qual o uso daquelas enfiadas de bolas do aritmômetro" (BORGES, 1884, p. 8).

Vemos assim que o Barão havia instalado um stand na Exposição para promover seu Colégio, então sob a direção de seus filhos, como, aliás, fizeram os grandes colégios particulares do Rio de Janeiro. Baseado no guia para os visitantes da Exposição, KUHLMAN JÚNIOR descreve assim a instalação:

A sala ocupada pelo colégio Abílio na Exposição apresentava vários instrumentos e aparelhos de ensino, muito deles importados: para as matemáticas (aritmética, geometria, mecânica), astronomia, física (hidrostática, pneumática, calor, óptica, eletricidade, magnetismo, acústica), química, geologia e mineralogia, botânica, zoologia, anatomia, coleções tecnológicas para lições sobre objetos(por exemplo, quadros do reino vegetal e cartas de cores para instrução primária), geografia, história, desenho e escrita, leitura, acessórios de ensino, educação física, e obras sobre educação oriundas de vários países (2001, p. 202).

Dentre esse conjunto de materiais didáticos, exibido em destaque, estava a invenção do Barão: o "aritmômetro fracionário", que naquela noite, conduzido para o palco, seria devidamente exibido e explicado.

Entusiasmado com o sucesso do aritmômetro e face à dificuldade dos meninos em aprender frações, o Barão relata que decidiu mandar construir esse "fraciômetro", invento capaz de realizar com as frações as mesmas operações que o aritmômetro fazia com os inteiros. Porém, o artista incumbido de fabricá-lo não compreendeu muito bem seu pensamento e o aparelho foi mal executado. Mesmo imperfeito, o instrumento "não deixou de prestar bons serviços no ensino dos quebrados", sendo utilizado no Colégio de Barbacena até aquela data (BORGES, 1884, p. 9). Motivado pelo anúncio da Exposição, o Barão ocupou-se então novamente de sua invenção produzindo o aparelho que estava apresentando ao público. Adverte que ele precisava "passar ainda por várias modificações", o que o qualificaria para ser "adotado nas escolas nacionais, e na dos países adiantados", para onde pretendia "remeter exemplares" (BORGES, 1884, p. 9). 


\section{(cc) $\mathrm{EY}$}

Antes de falar sobre seu aparelho e valendo-se do ábaco que, como veremos, fazia parte de sua invenção, o Barão passou a discorrer sobre a utilidade de se ensinar números "partindo de objetos à vista e tangíveis para os ausentes; do concreto para o abstrato; do conhecido para o desconhecido; subindo sempre lentamente, como por degraus pequenos e fáceis" (BORGES, 1884, p. 10). Do exposto ele conclui que "deve o mestre proceder na ordem seguinte: $1^{\circ}$ ) a ideia dos números representados por objetos presentes; $2^{\circ}$ ) a concepção dos números aplicados a objetos ausentes; $3^{\circ}$ a concepção dos números sem aplicação a objetos, isto é, abstratamente" (BORGES, 1884, p. 10-11). Para embasar seus argumentos, o Barão cita "um experimentado professor norteamericano", segundo o qual "o menino considera logo intuitivamente a unidade como uma medida e conseguintemente forma a ideia de mais e de menos, que é justamente a ideia de quantidade" (BORGES, 1884, p.12, grifos no original). Sua adesão ao credo então em voga do ensino intuitivo é manifesta em vários trechos de sua fala, por exemplo, quando ele critica o modo usual de ensino: "o método comum segue um processo inteiramente inverso do natural: querendo que o discípulo aprenda princípios gerais antes de haver adquirido as ideias particulares de que nascem aqueles princípios gerais ou regras” (BORGES, 1884, p. 15). Mais adiante, ele chama seu método de ensino de "indução analítica", isto é, "ensinar as regras pelos exemplos que fazem executar pelos discípulos, e não, como até agora, ensinar primeiro as regras e querendo que por meio delas descubram os discípulos, como devem ser executados os exemplos” (BORGES, 1884, p. 17). O Barão cita ainda Marie Pape-Carpentier, célebre publicista do ensino intuitivo no século XIX, que tinha várias de suas obras na Exposição (conforme BASTOS, 2010, p. 16), enfatizando a necessidade das frações serem ensinadas o quanto antes aos meninos, concluindo: "Eis o porque começamos, desde o primeiro ano, a dar a nossos jovens discípulos a ideia das partes iguais da unidade, ideia simples e clara, tão fácil de compreender quanto qualquer outra ideia simples e clara"(BORGES, 1844, p.18).

Finalmente ele começa a fazer a apresentação do seu aparelho dizendo que o que "era a princípio simples aritmômetro fracionário", devido à agregação de várias partes, umas inventadas por ele outras imitadas, "tornou-se um aparelho complexo que satisfaz cabalmente a várias exigências do ensino em uma escola primária", e que por isso ele o denominou "aparelho escolar 


\section{(cc) $\mathrm{EY}$}

múltiplo" BORGES, 1884, p. 18). ${ }^{2}$ Além do aritmômetro fracionário, o aparelho portava os seguintes dispositivos:

1) O que Borges chama de "contador de palitos, dito de Froebel", nossa atual caixa de numeração, cujos materiais se guardam numa gaveta (p. 31).

2) Um "contador vertico-horizontal, servindo ao mesmo tempo de ábaco ou contador de bolas", acrescido do traçado de 12 linhas verticais "marcando as classes e ordens dos números inteiros e decimais “(p. 34). O Barão diz que se inspirou em aparelho semelhante de Chaumeil, aparentemente o responsável por adaptar o ábaco para trabalhar o sistema métrico decimal. (p. 36).

3) Uma "imprensa escolar", espaço onde se pode encaixar letras grafadas em tabuinhas para formar sílabas e palavras como numa composição tipográfica, daí o nome (p.37).

4) Há também outro conjunto de tabuinhas onde estão grafados os algarismos para a composição do que ele chama de "numeração escrita" (p. 37).

5) Em uma das faces o aparelho traz um tabuleiro onde estão riscadas pautas musicais “apropriadas ao ensino do solfejo e do canto" (p. 38).

6) A parte posterior do aparelho dispõe de dois quadros negros para escrever números e letras (p. 39)

7) O aparelho traz também "sólidos aritméticos" por meio dos quais "os meninos veem com seus olhos, e podem tocar com os dedos a superfície de cada face do decímetro quadrado dividida em 100 centímetros quadrados" e do decímetro cúbico, dividido em 1000 centímetros cúbicos, "adquirindo logo ideias exatas do que sejam superfície e volume, e da base das medidas decimais, assim como o que seja quadrado e raiz quadrada, cubo e raiz cúbica" (p. 40).

8) Há ainda um "porta-mapas", onde mapas e estampas se conservam enrolados, prontos para serem usados nas aulas (p.41).

9) Os materiais avulsos ficam todos guardados em compartimentos dispostos numa caixa de madeira que serve de base para todo o aparelho (p.41).

\footnotetext{
${ }^{2}$ Não há nenhuma ilustração no texto. Os vários dispositivos estavam montados em um bastidor cúbico de madeira. $\mathrm{O}$ artigo de PAIS (2014, p. 13) reproduz um desenho do aritmômetro de Ahrens, um dos aparelhos que serviram de fonte de inspiração para o Barão.
}

Rev. Iberoam. Patrim. Histórico-Educativo, Campinas (SP), v. 5, p. 1-14, e019034, 2019. 


\section{$(\mathrm{cc}) \mathbf{E Y}$}

10) Consta ainda do instrumento um "aparelho cromático", que é como ele denomina o disco de Newton, para demonstrar a composição das cores por meio de uma placa circular giratória (p.42).

Conforme o Barão ia apresentando as várias utilidades de seu instrumento, ele ia dando exemplos concretos de sua aplicação em sala de aula. No que se segue trataremos apenas de sua apresentação do "aritmômetro fracionário", considerado por ele sua invenção mais importante. Para entendermos melhor esse instrumento trazemos na Figura 3, um aparelho semelhante idealizado pelo professor José Mariano Vallejo no início do século XIX e explicitamente inspirado nas "tábuas de Pestalozzi". Vallejo, tal como Borges, utiliza 12 arames horizontais para colocar os cilindros, ao invés dos 10 projetados por Pestalozzi, para aumentar o número de frações equivalentes possíveis de serem visualizadas no aparelho (conforme CARRILLO GALLEGO, 2018, p. 584-6). Uma diferença importante do aparelho do Barão é que nele os arames estavam dispostos "de modo a se poderem tornar livres à vontade por uma das pontas", podendo-se adicionar ou retirar cilindros por essas pontas conforme a necessidade imposta pelas operações (BORGES, 1884, p. 20).

FIGURA 3 - Tabuleiro de quebrados de Vallejo

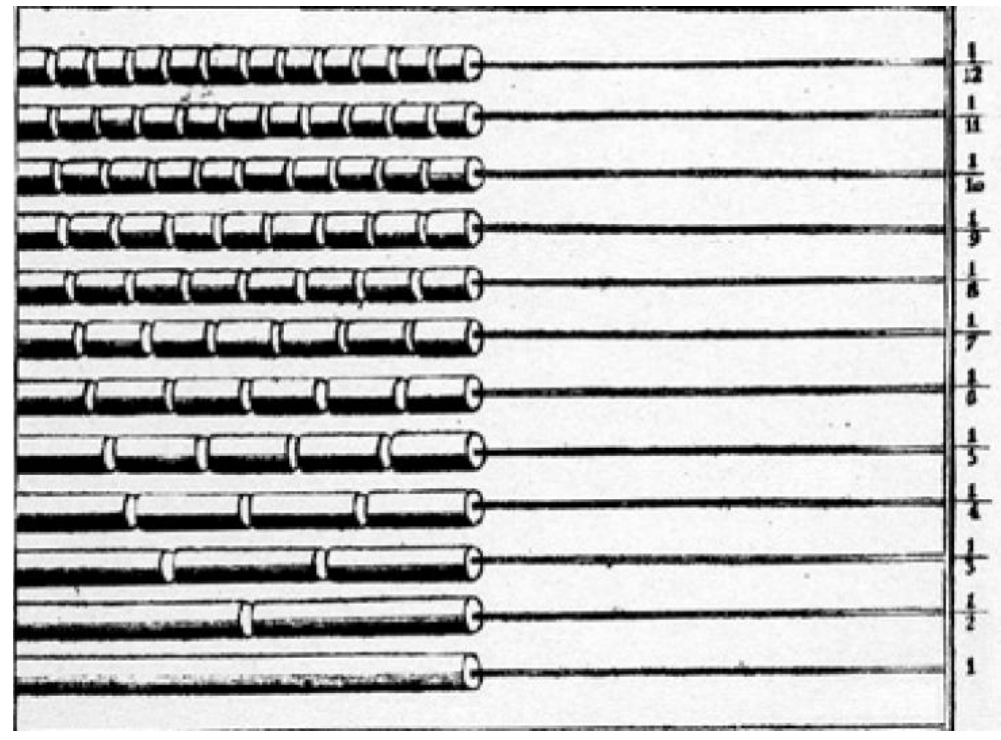

Fonte: CARRILLO GALLEGO, 2018, p. 585.

O Barão começa mostrando que o número de partes em que a unidade inferior é dividida exibe as frações próprias da unidade: 1/2, 1/3, 2/3, 1/4 e assim por diante. Como "cada vareta, desde a segunda, está a unidade dividida em números diferentes de partes iguais", temos aí os

Rev. Iberoam. Patrim. Histórico-Educativo, Campinas (SP), v. 5, p. 1-14, e019034, 2019. 


\section{$(c c)$ EY}

nomes das frações: um meio, um terço, e assim por diante até um doze avos. Portanto, escreve o Barão:

$$
1=2 / 2=3 / 3=4 / 4=5 / 5=6 / 6=7 / 7=8 / 8=9 / 9=10 / 10=\ldots
$$

Concluindo com a seguinte regra "a unidade é equivalente a qualquer fração, que tem o numerador e o denominador iguais" (BORGES, 1884, p. 22). Em seguida, o Barão explica o que são frações impróprias: “Ajuntando-se em qualquer das varetas uma ou mais frações cilíndricas iguais àquelas em que está dividida a unidade (...) teremos a unidade e mais tantas frações da mesma quanto tivermos ajuntado". Depois de dar alguns exemplos, o Barão enuncia então a regra: "sempre que uma fração tiver o numerador maior que o denominador, será fração imprópria, isto é, terá maior valor que a unidade" (BORGES, 1884, p. 23). E assim ele prossegue expondo a representação fracionária dos inteiros, redução de números mistos a frações, extração de inteiros contidos em uma fração imprópria e operações envolvendo frações, sempre finalizando com a enunciação de uma regra.

\section{CONSIDERAÇÕES FINAIS}

Excetuando-se os dois aritmômetros fracionários utilizados nos colégios do Barão, tudo indica que ele não produziu nenhum outro, embora outros professores possam ter copiado a ideia. No levantamento feito por Pais acerca dos aritmômetros escolares, ele encontrou apenas uma referência ao aparelho de Abílio Cesar Borges durante o Congresso de Instrução Primária realizado em Belo Horizonte em maio de 1927 (2014, p. 15). O grupo encarregado de discutir o "aparelhamento escolar" recomendou explicitamente que fossem adotados para o ensino de aritmética o "aparelho vertico-horizontal do Barão de Macaúbas, que modificou o de Chameuil” e o "Aritmômetro fracionário, invenção do mesmo autor" (Diário de Notícias, 17 de maio de 1929, p. 10). As citações das denominações dos aparelhos nos remetem diretamente à conferência do Barão, sugerindo que as recomendações tenham sido feitas por algum discípulo dos seus colégios, em Barbacena ou no Rio de Janeiro.

Melhor sorte teve o "aritmômetro de Ahrens" exposto no stand da Bélgica pelo seu inventor, Anton Ahrens, Irmão Lassalista (PAIS, 2014, p. 11). O sucesso desta exposição foi tamanho que foram encomendados na Europa, "para o ensino intuitivo do cálculo da metrologia", 


\section{(c) $)$ BY}

100 desses aparelhos para serem distribuídos nas escolas públicas do Rio de Janeiro (BRASIL, 1885, p.46). Os aparelhos foram efetivamente recebidos em 17 de junho de 1884 e distribuídos em 86 escolas. Antônio Herculano de Souza Bandeira Filho, inspetor da instrução pública no Rio de Janeiro de 1883 a 1884 e partidário do ensino intuitivo, que havia endossado a compra dos aparelhos, logo que foi nomeado Presidente da Província da Paraíba em 1885 conseguiu que o Ministério do Império enviasse para a Escola Normal por ele recém criada, "todos os objetos que costumam ser fornecidos para as escolas públicas da Corte" (PARAHYBA DO NORTE, 1886, p. 29). Dentre esses objetos constava um aritmômetro de Ahrens e também 200 exemplares da obra Desenho Linear de Abilio Cesar Borges, sugerindo que não havia aritmômetros fracionários disponíveis no Rio de Janeiro. Além da possível circulação desse aritmômetro na Paraíba, Pais sugere também que ele tenha sido usado no Amazonas, evidenciando a repercussão da Exposição no restante do país (2014, p. 13).

Encerrada a Exposição, decidiu-se criar um Museu Pedagógico Nacional para abrigar as doações de materiais didáticos oferecidas pelas empresas estrangeiras (COLLICHIO, 1987, p. 9). Este Museu funcionou até 1890, quando foi absorvido pelo Pedagogium, criado naquele ano e extinto em 1919, sendo seu patrimônio passado à então Escola Normal do Distrito Federal, depois Instituto de Educação. Quanto ao fracionômetro, voltou para o Colégio Abílio do Rio de Janeiro, dirigido agora pelos filhos do Barão, até meados da década de 1910, enquanto sua primeira versão continuava no colégio em Barbacena, transformado no Ginásio Mineiro em 1890. Ocupando um volume aproximado de um metro cúbico e feitos basicamente de madeira, dificilmente esses aparelhos sobreviveriam a tantas mudanças, ainda que continuassem no interior de instituições de ensino.

Em sua conferência, antes de exemplificar as operações que podem ser realizadas em seu aparelho, o Barão de Macaúbas recomendava:

Estes exemplos devem ser escritos nos quadros negros já mencionados, e depois reproduzidos concretamente no contador fracionário. É para notar-se a satisfação que mostram os discípulos ao verem com os olhos, nas frações sólidas, a exatidão do que exprimem os algarismos abstratos (BORGES, 1884, p. 21).

Ou seja, seu aparelho era de demonstração, feito muito mais para ver do que para ser manipulado pelos alunos e próprio para ser usado numa típica aula expositiva da época. Os avanços da pedagogia, especialmente da escola ativa, transformaram esses aparelhos de modo a que os 


\section{$(\mathrm{cc}) \mathrm{BY}$}

estudantes pudessem operar concretamente com os objetos. Não é difícil reconhecer no material dourado utilizado em nossas escolas a mesma funcionalidade do ábaco, enquanto o aritmômetro fracionário se transmutou no material didático criado pelo professor belga Cuisenaire ${ }^{3}$. O que nos mostra a importância da preservação do patrimônio escolar, quase sempre originado da prática de ensino, para a formação docente.

\section{REFERÊNCIAS}

BASTOS, Maria Helena Câmara. Educação infantil e ensino intuitivo: a contribuição de Marie Pape-Carpantier (1815-1878. Conjectura, Caxias do Sul, v. 15, n. 3, set./dez. 2010, p. 14-46.

BORGES, Abílio César. Conferência. Exposição Pedagógica do Rio de Janeiro. Rio de Janeiro: Tipografia Nacional, 1884.

BRASIL. Relatório do Ministro dos Negócios do Império do ano de 1884, João Florentino Meira de Vasconcellos. Apresentado à Assembleia Geral Legislativa em 29 de maio de 1885. Rio de Janeiro: Tipografia Nacional, 1885.

CARRILLO GALLEGO, Dolores. Los catálogos de material escolar como fuente de la historia de la educación matemática: el caso de los ábacos. Historia y Memoria de la Educación, 7 (2018): 573-613.

CASTANHA, André Paulo. Regimento Interno das escolas públicas da Corte de 1883: uma síntese da educação imperial. Revista HISTEDBR On-line, Campinas, número especial, p. 282296, maio de 2012.

COLLICHIO, Therezinha Ferreira. Dois eventos importantes para a história da educação brasileira: a Exposição Pedagógica de 1883 e as Conferências Populares da Freguesia da Glória. Revista da Faculdade de Educação da USP. São Paulo, vol.13, n. 2, jul./dez. 1987, p. 5-14.

\section{KUHLMAN JÚNIOR, Moysés. As grandes festas didáticas: a educação brasileira e as exposições internacionais (1862-1922). Bragança Paulista: EDUSF, 2001.}

OLIVEIRA, Marcus Aldenisson. Apropriações do método intuitivo para ensinar Aritmética em escolas primárias: uma análise da legislação educacional de estados brasileiros (1879-1930), 2014. Disponível em: http://seminariotematico.ufsc.br/files/2014/03/ASB4_Oliveira_art_DAC.pdf . Acesso em: 12 jun 2019.

\footnotetext{
${ }^{3}$ Georges Cuisinaire (1891-1980) fpi um professor belga que criou um material didático a partir de réguas com diferentes comprimentos e cores. Depois de experimentar por vários anos essas "barrinhas” em suas aulas, esse material didático, conhecido hoje como escala Cuisinaire, foi difundido mundialmente pelo professor egípcio radicado na Inglaterra, Caleb Gattegno.
}

Rev. Iberoam. Patrim. Histórico-Educativo, Campinas (SP), v. 5, p. 1-14, e019034, 2019. 
PAIS, Luiz Carlos. História dos aritmômetros escolares no ensino primário da matemática no Brasil(1883 - 1927). EM TEIA - Revista de Educação Matemática e Tecnológica Iberoamericana, v. 5, n. 3, 2014. Disponível em: https://periodicos.ufpe.br/revistas/emteia/article/view/2201/1772 . Acesso em 12 jun 2019. PARAHYBA DO NORTE, Província da. Mensagem do Presidente da Província da Parahyba, Antonio Herculano de Souza Bandeira Filho, a Assembléa Provincial em 1 de agosto de 1866. Disponível em:

http://ddsnext.crl.edu/titles $/ 178$ ?terms $=1886 \&$ item_id $=4090 \# ? \mathrm{~h}=1886 \& \mathrm{c}=4 \& \mathrm{~m}=87 \& \mathrm{~s}=0 \& \mathrm{cv}=1 \& \mathrm{r}=0$ \&xy wh=-1214\%2C0\%2C4075\%2C2875. Acesso em 15 jun 2019.

SAVIANI, Dermeval. Um barão brasileiro no congresso internacional de Buenos Aires: as ideias pedagógicas de Abílio César Borges, Barão de Macahubas. História da Educação. Pelotas. v.7, p. 41-58, abr. 2000 .

SCHÄRLIG, Alain. Compter avec des cailloux. Lausanne : PPUR, 2001.

Recebido em: 27 de julho 2019 Aceito em: 18 de dezembro de 2019 